Pacific Journal of Mathematics

A CLASS OF BILATERAL GENERATING FUNCTIONS FOR 


\title{
A CLASS OF BILATERAL GENERATING FUNCTIONS FOR CERTAIN CLASSICAL POLYNOMIALS
}

\author{
J. P. Singhal and H. M. SRIvastava
}

In this paper the authors first prove a theorem on bilateral generating relations for a certain sequence of functions. It is then shown how the main result can be applied to derive a large variety of bilateral generating functions for the Bessel, Jacobi, Hermite, Laguerre and ultraspherical polynomials, as well as for their various generalizations. Some recent results given by $W$. A. Al-Salam [1], S. K. Chatterjea [2], M. K. Das [3], S. Saran [6] and the present authors [9] are thus observed to follow fairly easily as special cases of the theorem proved in this paper.

Let the sequence of functions $\left\{S_{n}(x) \mid n=0,1,2, \cdots\right\}$ be generated by

$$
\sum_{n=0}^{\infty} A_{m, n} S_{m+n}(x) t^{n}=\frac{f(x, t)}{[g(x, t)]^{m}} S_{m}(h(x, t)),
$$

where $m$ is a nonnegative integer, the $A_{m, n}$ are arbitrary constants, and $f, g, h$ are arbitrary functions of $x$ and $t$.

In the present paper we first prove the following

TheOREM. For the $S_{n}(x)$ generated by (1), let

$$
F[x, t]=\sum_{n=0}^{\infty} a_{n} S_{n}(x) t^{n},
$$

where the $a_{n} \neq 0$ are arbitrary constants.

Then

$$
\begin{gathered}
f(x, t) F[h(x, t), y t / g(x, t)] \\
=\sum_{n=0}^{\infty} S_{n}(x) \sigma_{n}(y) t^{n},
\end{gathered}
$$

where $\sigma_{n}(y)$ is a polynomial of degree $n$ in $y$ defined by

$$
\sigma_{n}(y)=\sum_{k=0}^{n} a_{k} A_{k, n-k} y^{k} .
$$

We also show how this theorem can be applied to derive a large number of bilateral generating functions for those classical polynomial systems that satisfy a relationship like (1). In particular, we discuss the cases of the Bessel, Jacobi, Hermite, Laguerre and ultraspherical polynomials. 
2. Proof of the theorem. If we substitute for the coefficients $\sigma_{n}(y)$ from (4) on the right-hand side of (3), we shall get

$$
\begin{aligned}
\sum_{n=0}^{\infty} S_{n}(x) \sigma_{n}(y) t^{n} & =\sum_{n=0}^{\infty} S_{n}(x) t^{n} \sum_{k=0}^{n} a_{k} A_{k, n-k} y^{k} \\
& =\sum_{k=0}^{\infty} a_{k}(y t)^{k} \sum_{n=0}^{\infty} A_{k, n} S_{n+k}(x) t^{n} \\
& =f(x, t) \sum_{k=0}^{\infty} a_{k} S_{k}(h(x, t))\{y t / g(x, t)\}^{k},
\end{aligned}
$$

by using (1), and the theorem follows on interpreting this last expression by means of (2).

3. Applications. As a first instance of the applications of our theorem, we recall the following known generating function for the ultraspherical polynomials [5, p. 280]:

$$
\sum_{n=0}^{\infty}\left(\begin{array}{c}
m+n \\
n
\end{array}\right) P_{m+n}^{\lambda}(x) t^{n}=\rho^{-m-2 \lambda} P_{m}^{\lambda}\left(\frac{x-t}{\rho}\right),
$$

where $\rho=\left(1-2 x t+t^{2}\right)^{-1 / 2}$.

Formula (5) is of type (1) with $f=\rho^{-2 \lambda}, g=\rho, h=(x-t) / \rho$, and $A_{m, n}=\left(\begin{array}{c}m+n \\ n\end{array}\right)$, and therefore, our theorem, when applied to the ultraspherical polynomials, gives us

CoROLlary 1. If

$$
F[x, t]=\sum_{n=0}^{\infty} a_{n} P_{n}^{\lambda}(x) t^{n},
$$

then

$$
\rho^{-2 \lambda} F\left[\frac{x-t}{\rho}, \frac{y t}{\rho}\right]=\sum_{n=0}^{\infty} P_{n}^{\lambda}(x) b_{n}(y) t^{n},
$$

where, as well as in what follows,

$$
b_{n}(y)=\sum_{k=0}^{n}\left(\begin{array}{l}
n \\
k
\end{array}\right) a_{k} y^{k}
$$

Corollary 1 was proved recently by Chatterjea [2]. Note that in his long and involved derivation of Corollary 1, Chatterjea made use of the following formula of Tricomi:

$$
P_{n}^{\lambda}\left(\frac{x}{\sqrt{\left(x^{2}-1\right)}}\right)=\frac{(-1)^{n}\left(x^{2}-1\right)^{\lambda+(1 / 2) n}}{n !} \frac{d^{n}}{d x^{n}}\left\{\left(x^{2}-1\right)^{-\lambda}\right\} .
$$

Evidently, in view of the known generating function (5), formula (7) 
would follow from (6) and (8) in a straightforward manner, without using (9).

Next we consider the Laguerre polynomials which satisfy the relationship [5, p. 211]

$$
\begin{aligned}
& \sum_{n=0}^{\infty}\left(\begin{array}{c}
m+n \\
n
\end{array}\right) L_{m+n}^{(\lambda)}(x) t^{n} \\
& \quad=(1-t)^{-1-\lambda-m} \exp \left(\frac{-x t}{1-t}\right) L_{m}^{(\lambda)}\left(\frac{x}{1-t}\right),
\end{aligned}
$$

which is of type (1) with $f=(1-t)^{-1-\lambda} \exp \{-x t /(1-t)\}, g=(1-t)$, $h=x /(1-t)$, and $A_{m, n}=\left(\begin{array}{c}m+n \\ n\end{array}\right)$. Thus we arrive at the following special case of our theorem:

COROLLARY 2. If

$$
F[x, t]=\sum_{n=0}^{\infty} a_{n} L_{n}^{(\lambda)}(x) t^{n},
$$

then

$$
\begin{gathered}
(1-t)^{-1-\lambda} \exp \left(\frac{-x t}{1-t}\right) F\left[\frac{x}{1-t}, \frac{y t}{1-t}\right] \\
=\sum_{n=0}^{\infty} L_{n}^{(\lambda)}(x) b_{n}(y) t^{n} .
\end{gathered}
$$

Corollary 2 provides us with the corrected version of a result proved earlier by Al-Salam [1, p. 134].

On the other hand, if we consider the formula (see, for instance, [4], p. 58)

$$
\begin{aligned}
\sum_{n=0}^{\infty}\left(\begin{array}{c}
m+n \\
n
\end{array}\right) L_{m+n}^{(\lambda-m-n)}(x) t^{n} \\
=(1+t)^{\lambda-m} e^{-x t} L_{m}^{(\lambda-m)}(x(1+t)),
\end{aligned}
$$

we shall obtain the following particular case of our theorem:

COROLLARY 3. If

$$
F[x, t]=\sum_{n=0}^{\infty} a_{n} L_{n}^{(\lambda-n)}(x) t^{n},
$$

then

$$
\begin{gathered}
(1+t)^{\lambda} e^{-x t} F[x(1+t), y t /(1+t)] \\
=\sum_{n=0}^{\infty} L_{n}^{(\lambda-n)}(x) b_{n}(y) t^{n} .
\end{gathered}
$$


For the simple Bessel polynomials defined by $[5$, p. 293]

$$
y_{n}(x)={ }_{2} F_{0}\left[-n, n+1 ;-;-\frac{1}{2} x\right] \text {, }
$$

we have [3, p. 409]

$$
\begin{aligned}
& \sum_{n=0}^{\infty} y_{m+n}(x) \frac{t^{n}}{n !} \\
& \quad=(1-2 x t)^{-(m+1) / 2} \exp \left\{\frac{1-\sqrt{(1-2 x t)}}{x}\right\} y_{m}\left(\frac{x}{\sqrt{(1-2 x t)}}\right),
\end{aligned}
$$

and on comparing (17) with (1) we are led to the following result of Das [3, p. 410]:

COROLLARY 4. If

$$
F[x, t]=\sum_{n=0}^{\infty} a_{n} y_{n}(x) \frac{t^{n}}{n !},
$$

then

$$
\begin{aligned}
(1- & 2 x t)^{-1 / 2} \exp \left\{\frac{1-\sqrt{(1-2 x t)}}{x}\right\} F\left[\frac{x}{\sqrt{(1-2 x t)}}, \frac{y t}{\sqrt{(1-2 x t)}}\right] \\
= & \sum_{n=0}^{\infty} y_{n}(x) b_{n}(y) \frac{t^{n}}{n !} .
\end{aligned}
$$

Similarly, if we compare (1) with the known formula [5, p. 197]

$$
\sum_{n=0}^{\infty} H_{m+n}(x) \frac{t^{n}}{n !}=\exp \left(2 x t-t^{2}\right) H_{m}(x-t),
$$

where $H_{n}(x)$ denotes the Hermite polynomial of degree $n$ in $x$, we shall obtain a class of bilateral generating functions for these polynomials, given by

COROLlaRY 5. If

$$
F[x, t]=\sum_{n=0}^{\infty} \frac{a_{n}}{n !} H_{n}(x) t^{n},
$$

then

$$
\begin{gathered}
\exp \left(2 x t-t^{2}\right) F[x-t, y t] \\
=\sum_{n=0}^{\infty} H_{n}(x) b_{n}(y) \frac{t^{n}}{n !} .
\end{gathered}
$$

For the Jacobi polynomials we first observe that the special case 
$y=1$ of the bilinear generating relation (21), p. 465 of Srivastava [8] leads us to the elegant formula

$$
\begin{aligned}
& \sum_{n=0}^{\infty}\left(\begin{array}{c}
m+n \\
n
\end{array}\right) P_{m+n}^{(\alpha-m-n, \beta-m-n)}(x) t^{n} \\
&=\left\{1+\frac{1}{2}(x+1) t\right\}^{\alpha-m}\left\{1+\frac{1}{2}(x-1) t\right\}^{\beta-m} \\
& \times P_{m}^{(\alpha-m, \beta-m)}\left(x+\frac{1}{2}\left(x^{2}-1\right) t\right) .
\end{aligned}
$$

Note that the last formula (23) is a generalization of the well-known result

$$
\sum_{n=0}^{\infty} P_{n}^{(\alpha-n, \beta-n)}(x) t^{n}=\left\{1+\frac{1}{2}(x+1) t\right\}^{\alpha}\left\{1+\frac{1}{2}(x-1) t\right\}^{\beta},
$$

which follows at once from (23) when $m=0$.

A comparison of (23) with (1) yields

COROLlary 6. If

$$
F[x, t]=\sum_{n=0}^{\infty} a_{n} P_{n}^{(\alpha-n, \beta-n)}(x) t^{n},
$$

then

$$
\begin{aligned}
\{1+ & \left.\frac{1}{2}(x+1) t\right\}^{\alpha}\left\{1+\frac{1}{2}(x-1) t\right\}^{\beta} \\
& \times F\left[x+\frac{1}{2}\left(x^{2}-1\right) t, y t /\left\{1+\frac{1}{2}(x+1) t\right\}\left\{1+\frac{1}{2}(x-1) t\right\}\right] \\
= & \sum_{n=0}^{\infty} P_{n}^{(\alpha-n, \beta-n)}(x) b_{n}(y) t^{n} .
\end{aligned}
$$

Next we set $v=0$ in the bilinear generating relation (18), p. 464 of Srivastava [8]. On replacing $\alpha, \gamma$ and $\lambda$ by $1+\alpha+\beta, 1+\alpha$ and $1+\alpha+m$ respectively, it is easy to see that

$$
\begin{aligned}
\sum_{n=0}^{\infty}\left(\begin{array}{c}
m+n \\
n
\end{array}\right) P_{m+n}^{(\alpha, \beta-m-n)}(x) t^{n} \\
\quad=(1-t)^{\beta-m}\left\{1-\frac{1}{2}(x+1) t\right\}^{-\alpha-\beta-1} P_{m}^{(\alpha, \beta-m)}(X),
\end{aligned}
$$

where, for convenience,

$$
X=\left\{x-\frac{1}{2}(x+1) t\right\}\left\{1-\frac{1}{2}(x+1) t\right\}^{-1} .
$$


We thus obtain

COROLlaRy 7. If

$$
F[x, t]=\sum_{n=0}^{\infty} a_{n} P_{n}^{(\alpha, \beta-n)}(x) t^{n},
$$

then

$$
\begin{aligned}
& (1-t)^{\beta}\left\{1-\frac{1}{2}(x+1) t\right\}^{-\alpha-\beta-1} F[X, y t /(1-t)] \\
& =\sum_{n=0}^{\infty} P_{n}^{(\alpha, \beta-n)}(x) b_{n}(y) t^{n},
\end{aligned}
$$

where $X$ is given by (28).

Lastly, we recall the following generating relation $[9, \mathrm{p} .79$, eq. $(3.6)]$

$$
\begin{aligned}
\sum_{n=0}^{\infty}\left(\begin{array}{c}
m+n \\
n
\end{array}\right) G_{m+n}^{(\lambda)}(x, r, p, \alpha) t^{n} \\
=(1-\alpha t)^{-m-\lambda / \alpha} \exp \left[p x^{r}\left\{1-(1-\alpha t)^{-r / \alpha}\right\}\right] \\
\quad \times G_{m}^{(\lambda)}\left(x(1-\alpha t)^{-1 / \alpha}, r, p, \alpha\right),
\end{aligned}
$$

where the $G_{n}^{(\lambda)}(x, r, p, \alpha)$ are polynomials in $x^{r}$ introduced by us [9] in an attempt to provide an elegant unification of the various recent extensions of the classical Hermite and Laguerre polynomials given, for instance, by Gould and Hopper [4] and others referred to in our earlier paper [9]. A comparison of (31) with (1) would yield the following result:

\section{CoRollary 8. If}

$$
F[x, t]=\sum_{n=0}^{\infty} a_{n} G_{n}^{(\lambda)}(x, r, p, \alpha) t^{n},
$$

then

$$
\begin{aligned}
& (1-\alpha t)^{-\lambda / \alpha} \exp \left[p x^{r}\left\{1-(1-\alpha t)^{-r / \alpha}\right\}\right] F\left[x /(1-\alpha t)^{1 / \alpha}, y t /(1-\alpha t)\right] \\
& =\sum_{n=0}^{\infty} G_{n}^{(\lambda)}(x, r, p, \alpha) b_{n}(y) t^{n} .
\end{aligned}
$$

Corollary 8, which incorporates Corollaries 2 and 5 as its particular cases, was proved earlier by us $[9$, p. $82, \S 6]$ by using an operational technique.

Now we recall the sequence of functions $\left\{f_{n}(x) \mid n=0,1,2, \cdots\right\}$ defined by Rodrigues' formula 


$$
f_{n}(x)=\mu(n) \phi(x) \frac{d^{n}}{d x^{n}}\{\Psi(x)\},
$$

where $\phi(x)$ and $\Psi(x)$ are independent of $n$. By using Taylor's theorem it is readily seen that the $f_{n}(x)$ are generated by

$$
\begin{aligned}
\sum_{n=0}^{\infty} \frac{\mu(m)}{n ! \mu(m+n)} f_{m+n}(x) t^{n}=\frac{\phi(x)}{\phi(x+t)} f_{m}(x+t), & \\
& m=0,1,2, \cdots,
\end{aligned}
$$

which evidently is of type (1) with

$$
A_{m, n}=\frac{\mu(m)}{n ! \mu(m+n)}, f=\frac{\phi(x)}{\phi(x+t)}, g=1, h=x+t .
$$

Thus the sequence $\left\{f_{n}(x)\right\}$, considered recently by Saran [6], is merely a proper subset of $\left\{S_{n}(x)\right\}$ defined by the generating relation (1).

Consequently, as a very special case of our theorem we can obtain the following corollary which happens to be the main result of Saran's paper [6] :

Corollary 9. For the $f_{n}(x)$ defined by (34), let

$$
F[x, t]=\sum_{n=0}^{\infty} a_{n} f_{n}(x) t^{n},
$$

where the $a_{n} \neq 0$ are arbitrary constants.

\section{Then}

$$
\frac{\phi(x) F[x-t, y t]}{\phi(x-t)}=\sum_{n=0}^{\infty} \frac{(-t)^{n}}{n ! \mu(n)} f_{n}(x) c_{n}(y)
$$

where

$$
c_{n}(y)=\sum_{k=0}^{n}(-n)_{k} \mu(k) a_{k} y^{k} .
$$

By comparing (34) with Tricomi's formula (9) it would seem obvious that Corollary 1 , involving ultraspherical polynomials, is contained in Corollary 9. However, it may be pointed out that the scope of Corollary 9 is very limited, since Rodrigues formulas of most of the classical polynomials require that the function $\Psi(x)$, involved in (34), depend upon both $n$ and $x$. Besides, the factor $\mu(n)$ on the right-hand side of (34) is superfluous. Indeed, in equations (34), (35), (37), (38) and (39) one can replace, without any loss of generality, $f_{n}(x)$ by $\mu(n) f_{n}(x)$ and $a_{n}$ by $a_{n} / \mu(n), n=0,1,2, \cdots$.

In conclusion, we remark that by assigning special values to the 
arbitrary coefficients $a_{n}$ it is easy to obtain, from Corollaries 1 to 9 , a large variety of bilateral generating functions for the Bessel, Jacobi, Hermite, Laguerre and ultraspherical polynomials, and their generalizations studied earlier. For example, Corollary 2 would lead us fairly easily to a number of extensions of the well-known Hille-Hardy formula given, for instance, by Srivastava [7] and Weisner [10]. The details involved are quite straightforward and are, therefore, omitted.

\section{RERERENCES}

1. W. A. Al-Salam, Operational representations for the Laguerre and other polynomials, Duke Math. J., 31 (1964), 127-142.

2. S. K. Chatterjea, A bilateral generating function for the ultraspherical polynomials, Pacific J. Math., 29 (1969), 73-76.

3. M. K. Das, Sur les polynômes de Bessel, C. R. Acad. Sci. Paris. Sér. A 271 (1970), 408-411.

4. H. W. Gould and A. T. Hopper, Operational formulas connected with two generalizations of Hermite polynomials, Duke Math. J., 29 (1962), 51-63.

5. E. D. Rainville, Special functions, Macmillan Co., New York, 1960.

6. S. Saran, A general theorem for bilinear generating functions, Pacific J. Math., 35 (1970), 783-786.

7. H. M. Srivastava, An extension of the Hille-Hardy formula, Math. Comp., 23 (1969), 305-311.

8. - Some bilinear generating functions, Proc. Nat. Acad. Sci. U.S.A., 64 (1969), 462-465.

9. H. M. Srivastava and J. P. Singhal, A class of polynomials defined by generalized Rodrigues' formula, Ann. Mat. Pure Appl. Ser. IV, 90 (1971), 75-85. See also Abstract 71T-B16, Notices Amer. Math. Soc., 18 (1971), 252.

10. L. Weisner, Group-theoretic origins of certain generating functions, Pacific J. Math., 5 (1955), 1033-1039.

Received June 21, 1971. Supported in part by NRC grant A-7353. See Abstract 684-B14 in Notices Amer. Math. Soc., 18 (1971), p. 515.

UNIVERSITY OF JODHPUR

JODHPUR, INDIA

AND

UNIVERSITY OF VICTORIA

Victoria, BRITISH Columbia

CANAda 


\section{PACIFIC JOURNAL OF MATHEMATICS}

\section{EDITORS}

\section{H. SAMELSON}

Stanford University

Stanford, California 94305

\section{R. HOBBY}

University of Washington

Seattle, Washington 98105

\section{J. DugundjI}

Department of Mathematics University of Southern California Los Angeles, California 90007

RICHARD ARENS

University of California

Los Angeles, California 90024

\section{ASSOCIATE EDITORS}
E. F. BECKENBACH
B. H. NeumanN
F. WOLF
K. YOSHIDA

\section{SUPPORTING INSTITUTIONS}

\author{
UNIVERSITY OF BRITISH COLUMBIA \\ CALIFORNIA INSTITUTE OF TECHNOLOGY \\ UNIVERSITY OF CALIFORNIA \\ MONTANA STATE UNIVERSITY \\ UNIVERSITY OF NEVADA \\ NEW MEXICO STATE UNIVERSITY \\ OREGON STATE UNIVERSITY \\ UNIVERSITY OF OREGON \\ OSAKA UNIVERSITY
}

\author{
UNIVERSITY OF SOUTHERN CALIFORNIA \\ STANFORD UNIVERSITY \\ UNIVERSITY OF TOKYO \\ UNIVERSITY OF UTAH \\ WASHINGTON STATE UNIVERSITY \\ UNIVERSITY OF WASHINGTON \\ AMERICAN MATHEMATICAL SOCIETY \\ NAVAL WEAPONS CENTER
}

The Supporting Institutions listed above contribute to the cost of publication of this Journal, but they are not owners or publishers and have no responsibility for its content or policies.

Mathematical papers intended for publication in the Pacific Journal of Mathematics should be in typed form or offset-reproduced, (not dittoed), double spaced with large margins. Underline Greek letters in red, German in green, and script in blue. The first paragraph or two must be capable of being used separately as a synopsis of the entire paper. The editorial "we" must not be used in the synopsis, and items of the bibliography should not be cited there unless absolutely necessary, in which case they must be identified by author and Journal, rather than by item number. Manuscripts, in duplicate if possible, may be sent to any one of the four editors. Please classify according to the scheme of Math. Rev. Index to Vol. 39. All other communications to the editors should be addressed to the managing editor, Richard Arens, University of California, Los Angeles, California, 90024.

50 reprints are provided free for each article; additional copies may be obtained at cost in multiples of 50 .

The Pacific Journal of Mathematics is published monthly. Effective with Volume 16 the price per volume (3 numbers) is $\$ 8.00$; single issues, $\$ 3.00$. Special price for current issues to individual faculty members of supporting institutions and to individual members of the American Mathematical Society: $\$ 4.00$ per volume; single issues $\$ 1.50$. Back numbers are available.

Subscriptions, orders for back numbers, and changes of address should be sent to Pacific Journal of Mathematics, 103 Highland Boulevard, Berkeley, California, 94708.

PUBLISHED BY PACIFIC JOURNAL OF MATHEMATICS, A NON-PROFIT CORPORATION

Printed at Kokusai Bunken Insatsusha (International Academic Printing Co., Ltd.), 270, 3-chome Totsuka-cho, Shinjuku-ku, Tokyo 160, Japan. 


\section{Pacific Journal of Mathematics}

\section{Vol. 42, No. $3 \quad$ March, 1972}

Catherine Bandle, Extensions of an inequality by Pólya and Schiffer for vibrating membranes ................................ 543

S. J. Bernau, Topologies on structure spaces of lattice groups.......... 557

Woodrow Wilson Bledsoe and Charles Edward Wilks, On Borel product measures .......................................

Eggert Briem and Murali Rao, Normpreserving extensions in subspaces of

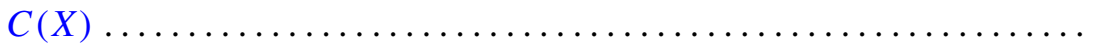

Alan Seymour Cover, Generalized continuation.................. 589

Larry Jean Cummings, Transformations of symmetric tensors .......... 603

Peter Michael Curran, Cohomology of finitely presented groups .......... 615

James B. Derr and N. P. Mukherjee, Generalized quasicenter and

hyperquasicenter of a finite group ...................... 621

Erik Maurice Ellentuck, Universal cosimple isols .................. 629

Benny Dan Evans, Boundary respecting maps of 3-mainfolds .......... 639

David F. Fraser, A probabilistic method for the rate of convergence to the

Dirichlet problem .................................. 657

Raymond Taylor Hoobler, Cohomology in the finite topology and Brauer

groups ..................................... 667

Louis Roberts Hunt, Locally holomorphic sets and the Levi form ........ 681

B. T. Y. Kwee, On absolute de la Vallée Poussin summability............ 689

Gérard Lallement, On nilpotency and residual finiteness in semigroups .... 693

George Edward Lang, Evaluation subgroups of factor spaces........... 701

Andy R. Magid, A separably closed ring with nonzero torsion pic ....... 711

Billy E. Rhoades, Commutants of some Hausdorff matrices ............. 715

Maxwell Alexander Rosenlicht, Canonical forms for local derivations . . . . 721

Cedric Felix Schubert, On a conjecture of L. B. Page ................ 733

Reinhard Schultz, Composition constructions on diffeomorphisms of $S^{p} \times S^{q}$

J. P. Singhal and H. M. (Hari Mohan) Srivastava, A class of bilateral generating functions for certain classical polynomials ....

Richard Alan Slocum, Using brick partitionings to establish conditions which insure that a Peano continuum is a 2-cell, a 2-sphere or an annulus...

James F. Smith, The p-classes of an $H^{*}$-algebra ...

Jack Williamson, Meromorphic functions with negative zeros and positive

poles and a theorem of Teichmuller ................. 